\title{
Práticas de leitura em Língua Portuguesa a partir da BNCC: em que se fundamentam e como realizá-las em sala de aula?
}

Reading Practices in Portuguese Language from BNCC: what are they based on and how to proceed inside the classroom?

\author{
Maria Aparecida Garcia Lopes-Rossi* \\ lopesrossi@uol.com.br \\ http://orcid.org/0000-0002-0888-7123
}

\section{Resumo}

A Base Nacional Comum Curricular - BNCC (BRASIL, 2018) prescreve práticas de leitura que devem ser implementadas na educação básica brasileira. No entanto, não explicita as bases teóricas em que fundamenta o Eixo Leitura em Língua Portuguesa, de forma que faltam subsídios para o aprimoramento teórico do professor, para o planejamento e para a implementação das práticas prescritas. Esta pesquisa teve o objetivo de investigar o Eixo Leitura da BNCC, Língua Portuguesa, da etapa do $6^{\circ}$ ao $9^{\circ}$ ano, no que se refere à proposta do documento e às suas bases teóricas e, ainda, às possibilidades didáticas dos principais conceitos envolvidos. Metodologicamente, é uma pesquisa qualitativa, sendo a primeira etapa do tipo documental, e a segunda, bibliográfica. Os resultados oferecem subsídios para o aprimoramento teórico do professor e para o planejamento de atividades de leitura teoricamente bem fundamentadas.

Palavras-chave: Eixo leitura; Habilidades de leitura; Estratégias de leitura; Educação básica; Letramento.

\section{Abstract}

The National Common Core Curriculum - BNCC (BRASIL, 2018) determines the pedagogical reading practices to be developed in basic education. However, this official curricular document does not clarify the theoretical foundation for the axis of reading in

\footnotetext{
* Universidade de Taubaté (UNITAU), Taubaté, SP, Brasil.
}

\section{LINHA DÁGUA}


Portuguese language classes. Therefore, there is a lack of theoretical support for the teacher's planning of reading practices. In this scenario, this research aims to investigate the axis of reading proposed by the BNCC regarding Portuguese language, from the sixth to the ninth grade, in terms of the document's proposal, its theoretical bases and the didactic possibilities of its key concepts. Methodologically, this is a qualitative research of documental and bibliographical approach. The results of the analyses offer subsidies, so that the Portuguese language teacher can prepare theory-based reading activities.

Keywords: Axis of reading; Reading abilities; Reading skills; Basic education; Literacy.

\section{Introdução}

Leitura em sala de aula, desenvolvimento de habilidades de leitura, formação do leitor e estratégias de leitura têm sido temas recorrentes na reflexão sobre o ensino de Língua Portuguesa no Brasil desde o início dos anos 80 do século XX, quando desenvolvimentos teórico-metodológicos da Linguística, da Psicolinguística e da Linguística Aplicada trouxeram novas perspectivas para o tratamento do texto e da leitura na escola. Cadernos PUC 16 (1983), Geraldi (1984) e Kato (1985) são três obras pioneiras, no contexto acadêmico brasileiro, na divulgação de que a decodificação de um texto, concebido como um repositório de informações completas e com sentido único, já não podia mais ser o padrão da leitura na escola.

A essas primeiras discussões sobre o tema, sucederam desenvolvimentos da abordagem cognitiva de leitura - sua aplicação a uma didática da leitura será apresentada na sequência deste artigo; pesquisas e publicações sobre ensino de leitura; e resultados exitosos de projetos de leitura relatados por professores e pesquisadores de todo o Brasil. Com tudo isso, ainda é relevante abordar o tema leitura na escola? Sim. Resultados de avaliações em larga escala, como os do Sistema Nacional de Avaliação da Educação Básica - SAEB (BRASIL, 2020) - a despeito de objeções que possam ser feitas a esse tipo de teste -, expõem a realidade de que a maior parte dos alunos brasileiros não desenvolve habilidades leitoras além do nível mais básico de compreensão. Os dados permitem afirmar que a Educação Básica brasileira precisa se beneficiar mais amplamente dos desenvolvimentos teóricos sobre a leitura.

A Base Nacional Comum Curricular - BNCC - foi aprovada pelo Ministério da Educação em 2017 e foi disponibilizada na internet, em sua versão final, no ano seguinte (BRASIL, 2018). É o documento norteador "para a formulação dos currículos dos sistemas e das redes escolares dos Estados, do Distrito Federal e dos municípios e das propostas pedagógicas das instituições escolares" (BRASIL, 2018, p. 8). Mantém dos Parâmetros Curriculares Nacionais - PCN (BRASIL, 1998) a concepção de linguagem como atividade discursiva, cognitiva e situada sócio-historicamente e as práticas de leitura de gêneros discursivos. A BNCC (BRASIL, 2018) amplia os objetos de leitura para além dos gêneros impressos já consagrados pela escola, incluindo gêneros multissemióticos e multimidiáticos. Assim, contempla também as produções de linguagem produzidas e veiculadas pelas atuais tecnologias digitais de informação e comunicação. Para a etapa do $6^{\circ}$ ao $9^{\circ}$ ano, são

\section{LINHA DÁGUA}


mencionados, para práticas de leitura, 55 gêneros discursivos, além dos "gêneros literários e artísticos diversos" (BRASIL, 2018, p. 157), e são prescritas 59 habilidades de leitura a serem desenvolvidas.

Esse documento normativo, por sua natureza, não tem o propósito de explicitar como as práticas de linguagem devem ser desenvolvidas em sala de aula. Fica a cargo das redes escolares, das equipes pedagógicas e dos professores o planejamento e as decisões sobre as formas de implementar as prescrições. Se, por um lado, isso garante certa autonomia aos educadores, por outro lado, impõe a difícil tarefa de interpretar o que se propõe em um documento sem qualquer explicitação de suas bases teóricas. No que se refere às práticas de leitura em Língua Portuguesa (Eixo Leitura), além desse problema, grande parte das prescrições se apresenta em forma de listas. Para que as práticas de leitura em sala de aula se insiram em situações de aprendizagem consistentes e não resultem apenas em atividades esparsas, algumas perguntas precisam ser respondidas: o que exatamente a BNCC propõe para o Eixo Leitura? Quais são os conceitos teóricos principais em que o documento se fundamenta? Como se podem articular didaticamente as dimensões para o tratamento das práticas leitoras, as habilidades de leitura, os objetos de conhecimento, os gêneros discursivos, entre outros conceitos mencionados no documento?

Em busca de respostas às perguntas, esta pesquisa teve o objetivo de investigar o Eixo Leitura da BNCC (BRASIL, 2018), Língua Portuguesa, da etapa do $6^{\circ}$ ao $9^{\circ}$ ano, no que se refere à proposta do documento e às suas bases teóricas e, ainda, às possibilidades didáticas dos principais conceitos envolvidos. Espera-se, assim, oferecer subsídios para a interpretação da proposta de práticas de leitura desse documento; para o aprimoramento teórico dos leitores presumidos da BNCC - em sua maioria, professores - que desejam estudar mais sobre o tema; e para o planejamento das práticas de leitura em sala de aula, naquilo que for exequível a partir desse documento.

Esta é uma pesquisa de cunho qualitativo, desenvolvida em duas etapas. A primeira foi do tipo documental, sendo sua fonte de dados a BNCC (BRASIL, 2018). Realizou-se a seleção de todos os trechos desse documento relativos ao Eixo Leitura, do $6^{\circ}$ ao $9^{\circ}$ ano, a síntese desses dados e a sua análise, buscando categorizá-los de acordo com suas filiações teóricas. Ainda que alguns dados numéricos sejam apresentados - quantidade de dimensões da leitura e de habilidades -, o enfoque da análise foi sempre o de buscar, na pesquisa bibliográfica, a segunda parte da pesquisa, as bases teóricas dos conceitos identificados. Essa segunda etapa bibliográfica da pesquisa foi finalizada com o exame do tema sob o enfoque de possibilidades de planejamento de uma pedagogia da leitura em sala de aula, de acordo com as prescrições do documento. $\mathrm{O}$ enquadramento da pesquisa nessa tipologia metodológica se baseia em Lakatos e Marconi (1991).

As seções a seguir expõem os resultados e a discussão dessas duas etapas da pesquisa. Finalizam o artigo as considerações finais e as referências.

\section{LINHA DÁGUA}




\section{As práticas leitoras e suas dimensões na BNCC (2018)}

A BNCC (BRASIL, 2018, p. 63) assume, para a área de Linguagens (Língua Portuguesa, Arte, Educação Física, Língua Inglesa), que "as atividades humanas realizam-se nas práticas sociais, mediadas por diferentes linguagens: verbal (oral ou visual-motora, como Libras e escrita), corporal, visual, sonora e, contemporaneamente, digital”. Por isso, os estudantes devem participar de práticas de linguagem variadas, ampliar seus conhecimentos sobre seus modos de funcionamento e, assim, ampliar seu repertório e sua capacidade de atuação na vida social.

Com relação ao componente Língua Portuguesa, que interessa, particularmente, a esta pesquisa, o documento manifesta-se por uma perspectiva enunciativo-discursiva de linguagem. Embora não explicite suas fontes, é possível identificar uma filiação teórica ao Círculo de Bakhtin em várias passagens a respeito da concepção de texto e de gêneros discursivos, conceitos que serão explicitados ao longo deste artigo. A BNCC faz considerações sobre o contexto contemporâneo e sobre a necessidade de a escola incorporar a seu currículo as linguagens midiáticas e digitais e seus modos de funcionamento, por meio de práticas de linguagem compreendidas em quatro eixos: oralidade, leitura/escuta; produção (escrita e multissemiótica) e análise linguística/semiótica. Essas práticas devem se efetivar por gêneros discursivos que circulam em cinco campos de atuação social priorizados pelo documento: vida pessoal, práticas de estudo e pesquisa, atuação na vida pública, jornalístico-midiático, artísticoliterário.

Sete dimensões para o tratamento das práticas leitoras, em todos esses campos, são apresentadas em um quadro de duas colunas, sem título, nas páginas 72-74. A coluna da esquerda nomeia cada dimensão, e a coluna da direita detalha 29 habilidades. Essas habilidades devem ser desenvolvidas ao longo da escolaridade, de forma contextualizada, por meio de atividades com crescente complexidade de demanda cognitiva.

A síntese dessa proposta é apresenta no quadro 1, a seguir, em que as sete dimensões das práticas leitoras são reproduzidas na primeira coluna; uma síntese das habilidades referentes a cada dimensão é apresentada na segunda coluna; e os conceitos teóricos mencionados no texto do quadro da BNCC (BRASIL, 2018) ou inferidos na sua leitura são relacionados na terceira coluna. Após o quadro, seguem considerações a partir de um olhar analítico para essas dimensões das práticas leitoras, ancorado na pesquisa bibliográfica sobre os conceitos que despontaram como principais na proposta. Busca-se, também, um caminho para a didatização de todo esse conjunto de informações sobre leitura, que o documento apresenta em forma de listas diagramadas em quadros. 
Quadro 1. Síntese das dimensões das práticas leitoras e conceitos relacionados

\begin{tabular}{|c|c|c|}
\hline $\begin{array}{c}\text { Dimensões das práticas } \\
\text { leitoras }\end{array}$ & Síntese das habilidades & $\begin{array}{c}\text { Conceitos teóricos } \\
\text { relacionados }\end{array}$ \\
\hline $\begin{array}{l}\text { "Reconstrução e reflexão } \\
\text { sobre as condições de } \\
\text { produção e recepção dos } \\
\text { textos pertencentes a } \\
\text { diferentes gêneros e que } \\
\text { circulam nas diferentes } \\
\text { mídias e esferas/campos } \\
\text { de atividade humana" }\end{array}$ & $\begin{array}{l}\text { Cinco habilidades a respeito: do contexto sócio- } \\
\text { histórico de produção e circulação do gênero } \\
\text { discursivo alvo da leitura; de como suas } \\
\text { características composicionais são determinadas } \\
\text { por esse contexto; de como as tecnologias de } \\
\text { comunicação e informação contemporâneas } \\
\text { atuam na produção, circulação e transformação } \\
\text { de gêneros discursivos; e da necessidade de } \\
\text { contemplar os novos e multiletramentos para } \\
\text { apreciação e compreensão ética, estética, política } \\
\text { e ideológica dos textos. }\end{array}$ & $\begin{array}{l}\text { Gênero discursivo } \\
\text { Novos e } \\
\text { multiletramentos }\end{array}$ \\
\hline $\begin{array}{l}\text { "Dialogia e relação entre } \\
\text { textos" }\end{array}$ & $\begin{array}{l}\text { Duas habilidades referentes à percepção: de } \\
\text { vozes presentes no texto por meio de marcas } \\
\text { linguísticas e de relações de intertextualidade e } \\
\text { interdiscursividade. }\end{array}$ & $\begin{array}{l}\text { Dialogia } \\
\text { Intertextualidade } \\
\text { Interdiscursividade }\end{array}$ \\
\hline $\begin{array}{l}\text { "Reconstrução da } \\
\text { textualidade, recuperação } \\
\text { e análise da organização } \\
\text { textual, da progressão } \\
\text { temática e } \\
\text { estabelecimento de } \\
\text { relações entre as partes do } \\
\text { texto" }\end{array}$ & $\begin{array}{l}\text { Três habilidades referentes à percepção: de } \\
\text { relações entre partes do texto (repetições, } \\
\text { substituições e outros elementos coesivos); de } \\
\text { relações lógico-discursivas; e de hierarquização } \\
\text { de informações do texto. }\end{array}$ & $\begin{array}{l}\text { Coesão referencial } \\
\text { Coesão sequencial } \\
\text { Organização } \\
\text { textual }\end{array}$ \\
\hline $\begin{array}{l}\text { "Reflexão crítica sobre as } \\
\text { temáticas tratadas e } \\
\text { validade das } \\
\text { informações" }\end{array}$ & Uma habilidade referente à leitura crítica & Leitura crítica \\
\hline $\begin{array}{l}\text { "Compreensão dos efeitos } \\
\text { de sentido provocados } \\
\text { pelos usos de recursos } \\
\text { linguísticos e } \\
\text { multissemióticos em } \\
\text { textos pertencentes a } \\
\text { gêneros diversos" }\end{array}$ & $\begin{array}{l}\text { Três habilidades relacionadas à identificação de } \\
\text { implícitos e efeitos de sentido referentes a } \\
\text { recursos expressivos da linguagem verbal, da } \\
\text { linguagem não verbal e da linguagem sonora. }\end{array}$ & $\begin{array}{l}\text { Leitura inferencial } \\
\text { Multissemiose }\end{array}$ \\
\hline $\begin{array}{l}\text { "Estratégias e } \\
\text { procedimentos de leitura" }\end{array}$ & $\begin{array}{l}\text { Treze habilidades cognitivas envolvidas no } \\
\text { processo de leitura. Referem-se à seleção de } \\
\text { procedimentos de leitura adequados aos } \\
\text { objetivos, aporte de conhecimentos prévios, } \\
\text { levantamento de hipóteses, localização de } \\
\text { informações, inferências diversas, articulação do } \\
\text { verbal com outras linguagens, tratamento das } \\
\text { informações, manejo da não linearidade da } \\
\text { leitura de hipertextos. }\end{array}$ & $\begin{array}{l}\text { Procedimentos de } \\
\text { leitura } \\
\text { Estratégias } \\
\text { cognitivas } \\
\text { Estratégias } \\
\text { metacognitivas } \\
\text { Habilidades de } \\
\text { leitura }\end{array}$ \\
\hline $\begin{array}{l}\text { "Adesão às práticas de } \\
\text { leitura" }\end{array}$ & $\begin{array}{l}\text { Duas habilidades relativas a interesse, } \\
\text { envolvimento e receptividade do aluno às } \\
\text { diversas propostas e experiências de leitura. }\end{array}$ & Motivação \\
\hline
\end{tabular}

Fonte: Elaborado pela autora, a partir de Brasil (2018, p. 72-74).

\section{LINHA DÁGUA}


Da perspectiva do leitor preocupado com a implementação das práticas de leitura em sala de aula, é possível supor indagações como: essas dimensões são todas da mesma natureza teórica? Estão apresentadas em uma ordem de organização das atividades em sala de aula? São sempre obrigatórias ou possíveis em um trabalho com leitura de um determinado gênero discursivo? Esses conceitos mencionados ou inferidos procedem da mesma base teórica? Não há uma definição nem muita clareza a respeito do termo dimensão, mas é possível afirmar que as sete dimensões não são da mesma natureza. Podem ser organizadas em três grupos.

No primeiro grupo, incluem-se as três primeiras dimensões e a quinta dimensão, que remetem à compreensão dos textos tomados como exemplares de gêneros discursivos ou enunciados concretos situados e constituídos dialogicamente em contextos sócio-históricos. Referem-se a propriedades constitutivas de gêneros discursivos, numa perspectiva de Bakhtin (2003) e Bakhtin/Volochínov (2006), para citar apenas duas obras mais conhecidas do Círculo de Bakhtin. Observam-se algumas articulações entre características constitutivas dos gêneros discursivos e outras abordagens teóricas. Uma delas é entre o conceito de dialogia, central na concepção bakhtiniana de linguagem, e os de intertextualidade e de interdiscursividade. São conceitos mencionados na segunda dimensão, que guardam certa relação por se referirem às relações que os enunciados estabelecem com outros enunciados e com vozes sociais. No entanto, sem o devido subsídio teórico, esses três conceitos podem ser confundidos, e a dialogia pode ser minimizada ou ignorada nas práticas de leitura.

As materialidades verbal e não verbal (semiótica) dos gêneros discursivos são contempladas na terceira e na quinta dimensão. A terceira refere-se a elementos de coesão referencial e de coesão sequencial, conceitos da Linguística Textual, desenvolvidos por Fávero (2006), entre outros autores, e à organização textual. Pela falta de clareza do documento a esse respeito, a organização textual poderá vir a ser abordada por perspectivas estruturais ou tipológicas (descrição, narração, dissertação). No entanto, essa alternativa não é a melhor. O ideal é que seja compreendida da perspectiva da organização típica do gênero discursivo alvo da leitura, organização essa engendrada pelas muitas condições determinantes das esferas de produção e de circulação do gênero. A compreensão de outros aspectos da dimensão linguística de um gênero discursivo é prevista na quinta dimensão de leitura, que também inclui a composição não verbal (semiótica) dos gêneros contemporâneos, com destaque para as decorrentes das novas tecnologias digitais de informação e comunicação. Nesse aspecto, a leitura de gêneros multissemióticos na escola vai ao encontro da proposta dos Novos e multiletramentos (LEMKE, 2010). As propriedades dos gêneros discursivos serão detalhadas na seção 2 .

Um segundo agrupamento proposto por esta pesquisa inclui "Reflexão crítica sobre as temáticas tratadas e validade das informações" (quarta dimensão) e "Estratégias e procedimentos de leitura" (sexta dimensão). Essas dimensões da leitura são detalhadas por habilidades expressas por verbos que remetem a categorias do domínio cognitivo, como relacionar, analisar, refletir, identificar, selecionar. Referem-se a processos sociocognitivos da

\section{LINHA DÁGUA}


compreensão, relacionados a vários conceitos que precisam ser explicitados, para que possam ser articulados com as propriedades dos gêneros discursivos, em práticas escolares de leitura. Também precisa ficar claro o que são procedimentos, estratégias e habilidades de leitura. Os aspectos sociocognitivos da leitura serão detalhados na seção 3.

Finalizando a primeira parte da análise das dimensões das práticas leitoras sintetizadas no quadro 1, destaca-se a sétima dimensão: Adesão às práticas de leitura. Essa é de natureza totalmente diferente das anteriores. Motivação é um conceito da Psicologia, definido de muitas maneiras, como mostra o levantamento de Todorov e Moreira (2005) sobre os usos do termo. Para qualquer uma das definições, a motivação é um comportamento complexo, que depende de uma série de circunstâncias. A motivação para a leitura no contexto escolar, pode-se supor, depende muito mais da forma como as situações de leitura serão propostas e desenvolvidas, com a mediação do(a) professor(a), do que de uma motivação interna e individual do estudante. Há muito a ser considerado sobre esse tema, para além dos limites desta pesquisa. Por isso, esse item do quadro 1 não será objeto de explicitação teórica. Sobre isso, conclui-se que mostrar-se interessado, envolvido e receptivo não pode ser colocado na mesma categoria das demais habilidades de leitura, que podem ser desenvolvidas ao longo da escolaridade, por meio de estratégias metacognitivas, acompanhadas pelo professor (VIANA et al., 2017; VIANIN, 2013).

As seções a seguir expõem a pesquisa bibliográfica sobre os conceitos referentes aos gêneros discursivos e aos aspectos sociocognitivos da leitura, na busca de formas mais efetivas de didatização das práticas de leitura na Educação Básica.

\section{Gêneros discursivos em práticas de leitura}

O conceito de gênero discursivo deve ser compreendido no contexto das ideias do Círculo de Bakhtin, um grupo de filósofos russos que elaborou um amplo conjunto de reflexões sobre a linguagem, na primeira metade do século XX, atualmente, denominado perspectiva dialógica da linguagem, perspectiva enunciativo-discursiva de linguagem ou análise dialógica do discurso. O grupo não tinha como foco o ensino e a aprendizagem de línguas, mas suas ideias influenciaram, fortemente, um deslocamento de ordem metodológica no ensino de línguas: do sistema linguístico para o enunciado (OLIVEIRA, 2002). O conceito de gênero discursivo (do discurso) é central nas práticas de linguagem prescritas pela BNCC (BRASIL, 2018).

Os gêneros discursivos são enunciados concretos, produções sociais, culturais, históricas pelas quais se realiza toda comunicação discursiva oral ou escrita. Os campos de atividades humanas moldam inúmeros gêneros discursivos, num processo complexo, dinâmico e histórico, como explica Bakhtin (2003). Essas produções de linguagem são reconhecidas e nomeadas pelos participantes das interações sociais. Nas esferas do cotidiano (infraestrutura), são produzidos gêneros primários, tais como diálogo, carta familiar, bilhete, lista de compras,

\section{LINHA D'́GUA}


cantigas de roda, receita. Esferas sociais institucionalizadas, marcadas pelas ideologias oficiais (superestrutura), produzem gêneros discursivos secundários, tais como: conferência, palestra, arguição, conto, poema, romance, história em quadrinhos, charge, propaganda social, anúncio publicitário, rótulo, notícia, artigo de opinião, reportagem de divulgação científica, verbete de dicionário, bula de remédio. A BNCC (BRASIL, 2018) determina, a partir do $6^{\circ}$ ano, práticas de linguagem com gêneros discursivos secundários.

A perspectiva bakhtiniana de linguagem, por entender que "A língua vive e evolui historicamente na comunicação verbal concreta" (BAKHTIN/VOLOCHÍNOV, 2006, p. 128), oferece explicação para o fato de que certos gêneros passam a ter um uso restrito ou deixam de ser produzidos e que outros, pela dinâmica das tecnologias de informação e comunicação, se modificam ou são criados. A BNCC (BRASIL, 2018) contempla essa dinâmica da língua propondo práticas de linguagem com gêneros discursivos emergentes e multissemióticos.

O falante (ou escritor), a partir de uma intenção discursiva (vontade discursiva, projeto de discurso, propósito comunicativo), identifica e escolhe um gênero que lhe permita realizar seu intento. No entanto, não escolhe livremente os elementos que comporão seu enunciado, como explica Bakhtin (2003). A individualidade ou subjetividade do falante ou escritor moldase às características típicas do gênero escolhido, que atendem às especificidades da situação de comunicação, ou contexto sócio-histórico de produção, de circulação, de recepção. $\mathrm{Na}$ afirmação de Bakhtin/Volochínov (2006):

[...] a enunciação humana mais primitiva, ainda que realizada por um organismo individual, é, do ponto de vista do seu conteúdo, de sua significação, organizada fora do indivíduo pelas condições extra-orgânicas do meio social. A enunciação enquanto tal é um puro produto da interação social, quer se trate de um ato de fala determinado pela situação imediata ou pelo contexto mais amplo que constitui o conjunto das condições de vida de uma determinada comunidade linguística (BAKHTIN/VOLOCHÍNOV, 2006, p. 128).

O caráter social e situado da linguagem humana é tão determinante na concepção bakhtiniana de linguagem que esses autores estabelecem que o estudo da língua deve sempre começar com "As formas e os tipos de interação verbal em ligação com as condições concretas em que [a língua] se realiza" (BAKHTIN/VOLOCHÍNOV, 2006, p. 129). Isso significa que qualquer trabalho na perspectiva dos gêneros discursivos deve sempre partir dos aspectos sóciohistóricos da situação de enunciação. Com base nesses pressupostos, qualquer prática de leitura em sala de aula deve começar com o que a BNCC (BRASIL, 2018, p. 72) denominou de dimensão da "Reconstrução e reflexão sobre as condições de produção e recepção dos textos pertencentes a diferentes gêneros e que circulam nas diferentes mídias e esferas/campos de atividade humana". A partir do contexto sócio-histórico (esferas de produção e de circulação), determinam-se as dimensões constitutivas materializadas e essenciais de qualquer exemplar de um gênero discursivo: conteúdo temático (tema), estilo da linguagem e construção composicional típica.

\section{LINHA DÁGUA}


O tema não é um assunto específico, definido a priori. Precisa ser compreendido no todo da enunciação, pelo que ele significa no momento da produção e da recepção do texto, em diálogo (relações dialógicas) com enunciados presentes, passados e futuros. É por isso que se considera que o tema de um texto é sempre único e irrepetível, como o é cada enunciado concreto. Isso porque, como fenômeno sócio-histórico, todo texto é uma manifestação linguística que não pode ser dissociada de seus falantes e de seus atos, das esferas sociais, dos valores ideológicos (BAKHTIN, 2003).

O estilo é uma propriedade do gênero discursivo, não uma característica do autor. As escolhas linguísticas (léxico, estruturas gramaticais) são determinadas pela função do gênero, pelas condições determinantes de sua esfera de produção e de circulação, como explica Bakhtin (2003, p. 266). Por isso, o estilo é indissociável da situação de comunicação, inclusive, dos tipos de relação do falante ou escritor com os outros participantes da cena da enunciação. A personalidade individual ou o estilo individual do autor pode se revelar, mas dentro do estilo do gênero, sendo os gêneros artístico-literários e publicitários os que mais permitem variações.

A dimensão composicional do enunciado se materializa, no texto escrito, pelos elementos verbo-visuais, observáveis no suporte em que o texto está gravado, seja papel, seja outro. Os componentes verbais (linguísticos) se organizam e permitem o desenvolvimento do tema de acordo com o estilo, com o propósito e com as características do gênero. $\mathrm{O}$ artigo de opinião, por exemplo, mantém uma formalidade determinada pela esfera jornalística escrita, busca defender uma ideia com um encadeamento lógico e bem articulado de suas proposições, organizadas em tese, argumentos, contra-argumentos, conclusão. A organização textual de cada gênero precisa ser estudada e compreendida de maneira única. Lopes-Rossi (2015) comenta que, mesmo gêneros que se organizam de forma tipicamente narrativa, como conto maravilhoso, conto fantástico e fábula, por exemplo, não podem ser descritos pelos elementos normalmente citados como constitutivos do enredo da narrativa: apresentação da situação inicial, complicação (conflito), clímax, resolução, desfecho. Essa tipologia, explica a autora, baseia-se em elementos mais gerais da organização narrativa, que não revelam especificidades e distinções da narrativa de cada um dos gêneros citados nem de muitos outros gêneros narrativos. O que há de específico nos elementos que compõem a narrativa de cada um desses gêneros precisa ser objeto de análise. A situação inicial de um conto maravilhoso é diferente da situação inicial de um conto fantástico, por exemplo. E assim será com os outros elementos.

Outros componentes linguísticos dos gêneros discursivos, como mecanismos de coesão referencial e coesão sequencial, recursos linguísticos, estrutura sintática e vocabulário, não podem ser descartados no estudo, na leitura e na produção de gêneros discursivos. No entanto, não podem ser abordados na escola como o que Bakhtin (2003) denomina de unidades da língua, que são descontextualizadas, desprovidas de entonação expressiva e de autoria. Devem ser abordados como o que o autor denomina unidades do discurso, ou seja, formas com sentidos tecidos na esfera de produção e nas relações dialógicas do enunciado. A BNCC (BRASIL, 2018) assume a perspectiva bakhtiniana quando determina o trabalho com habilidades de leitura referentes à compreensão dos efeitos de sentido dos recursos linguísticos.

\section{LINHA D'́GUA}


Os enunciados escritos são compostos também por elementos visuais (imagens, cores, elementos de diagramação, infográficos, entre outros). Os digitais podem incorporar elementos sonoros ou outros. Essa articulação de linguagens foi denominada de multimodalidade (DIONÍSIO, 2005) e de multissemiose (LEMKE, 2010). A partir da materialidade verbo-visual e de alguns elementos de seu modo de circulação, pode-se reconhecer o gênero em que o texto se insere já a partir do primeiro contato visual com ele, caso apresente características composicionais mais estáveis e fixas. Assim como outros componentes do enunciado, os visuais devem ser compreendidos no contexto dos posicionamentos bakhtinianos sobre a linguagem, sobre os sujeitos, sobre a vida (BRAIT, 2016).

Nesse ponto, a abordagem bakhtiniana se encontra com os conceitos de Novos e Multiletramentos. A proposta dos Novos Estudos do Letramento iniciou-se nos anos 1980, defendendo a heterogeneidade das práticas sociais de leitura e de escrita, os usos sociais da linguagem na vida cotidiana e as culturas locais, explica Rojo (2010). A autora observa que o mundo contemporâneo exige novos letramentos, multissemióticos e multimidiáticos, que se configuram em contextos de produção e de circulação mais complexos, em diálogo com outros discursos. Comenta a autora que as práticas de letramento se dão por meio de exemplares de gêneros discursivos e que a discussão bakhtiniana sobre a linguagem e as esferas de circulação dos discursos dão especificidade e detalhamento às noções de letramento.

Lemke (2010, p. 457) também vincula os letramentos aos gêneros discursivos, porque "Um letramento é sempre um letramento em algum gênero e deve ser definido com respeito aos sistemas sígnicos empregados, às tecnologias materiais usadas e aos contextos sociais de produção, circulação e uso de um gênero particular". Um gênero multimidiático só pode ser interpretado como parte de práticas culturais de uma determinada comunidade. Nunca se limita apenas ao autor e ao leitor. Essa interpretação requer uma série de habilidades específicas do leitor para cada gênero multimidiático, pois cada um se realiza numa rede de práticas e numa comunidade de comunicação específica.

Condições de produção e de circulação, intenção discursiva, conteúdo temático, estilo e construção composicional são marcados pelas relações dialógicas da linguagem, uma propriedade unificadora do pensamento bakhtiniano, de acordo com Fiorin (2006). Isso porque "Todo enunciado concreto é um elo na cadeia da comunicação discursiva de um determinado campo" (BAKHTIN, 2003, p. 296) e não pode ser compreendido fora dessa cadeia. Dessa forma, os sujeitos estão sempre apreendendo vozes sociais, que vão se reproduzindo ao longo da história. Os sentidos das palavras não vêm do dicionário e não são construídos pela consciência isolada de um sujeito. As palavras significam no todo do enunciado e não são neutras; elas chegam ao falante ou ao escritor ou ao leitor "cheias de ecos de outros enunciados" (BAKHTIN, 2003, p. 294). Assim, cada enunciado é pleno de palavras dos outros, carregadas de expressão e tom valorativo, reelaborado e reacentuado.

Dialogia não deve ser confundida com intertextualidade. Explica Fiorin (2006) que intertextualidade se refere a relações entre textos materializadas linguisticamente. É um tipo de relação dialógica muito restrita. Outro tipo é a interdiscursividade, que é a relação entre

\section{LINHA DÁGUA}


enunciados não explicitada ou materializada nos textos. Pereira (1998) comenta que a intertextualidade pode ser também não verbal, observada em textos, canções, obras de arte, detalhes arquitetônicos. Sua compreensão requer conhecimentos prévios do leitor, repertório. As atividades de leitura devem contribuir para que o leitor interprete as implicações de sentido das intertextualidades, pois elas não são gratuitas.

Os conceitos de intertextualidade e interdiscursividade não têm a amplitude do conceito de dialogismo. Este, no sentido mais amplo, é "o princípio de constituição do indivíduo e o seu princípio de ação" (FIORIN, 2006, p. 55), porque a consciência se constrói na interação social, pela história. A apreensão de vozes sociais se dá em atitude responsiva ativa dos sujeitos. $\mathrm{O}$ ouvinte de uma comunicação discursiva - e podemos entender o mesmo para o leitor -, no seu processo de compreensão do enunciado, explica Bakhtin (2003, p. 271), "concorda ou discorda dele (total ou parcialmente), completa-o, aplica-o, prepara-se para usá-lo, etc”. Nesse sentido, toda compreensão provoca uma resposta, ainda que não de forma imediata ou explícita, e estabelece ligações também com enunciados futuros. Ao mesmo tempo em que o sujeito se constitui nesse contexto social, ele reage e responde, participa do diálogo social.

Durante a leitura, as intertextualidades linguísticas ou imagéticas precisam ser compreendidas, mas as práticas de leitura devem promover um nível de discussão e de interpretação dos textos que, provavelmente, em seu último estágio, chegue ao nível da percepção de relações dialógicas do enunciado. O leitor, portanto, precisa perceber outros enunciados que o texto ecoa, como o tema do texto se configura no contexto sócio-histórico da situação enunciativa, como o autor se posiciona, como a construção composicional do texto foi pensada para efetivar o projeto enunciativo do autor, de acordo com o propósito comunicativo do gênero. Fiorin $(2009$, p. 53) afirma que "[...] sem perceber as relações dialógicas, não se chega à compreensão". Por isso, as propriedades dos gêneros discursivos e os outros conceitos expostos nesta seção precisam ser articulados com pressupostos teóricos sobre leitura, para serem viabilizados em práticas de leitura em sala de aula.

\section{Aspectos sociocognitivos da leitura}

A BNCC (BRASIL, 2018, p. 71) assume que a compreensão textual se constitui "da interação ativa do leitor/ouvinte/espectador com os textos escritos, orais e multissemióticos". Relaciona 58 habilidades de leitura, nas quais explicita aspectos cognitivos envolvidos no processo de leitura, como: estratégias de leitura, inferência, sumarização, processos de resolução de problemas, planejamento e monitoração da compreensão, levantamento de hipóteses, acionamento de conhecimentos prévios. Fica, assim, subentendida a filiação teórica do documento a uma abordagem sociocognitiva de leitura.

Os estudos sob a perspectiva da cognição e, mais recentemente, da sociocognição, já mostraram que é possível e muito desejável que estratégias metacognitivas de leitura e pensamento crítico sejam ensinados desde os primeiros anos de escolaridade, como aponta a

\section{LINHA DÁGUA}


síntese bibliográfica das décadas de 80 e 90 do século XX apresentada por Taglieber (2000). O desenvolvimento de habilidades de leitura, a partir de estratégias metacognitivas aprendidas na escola, tem sido endossado por pesquisadores brasileiros (KOCH; ELIAS, 2006) e de várias partes do mundo, como Butlen (2015), Solé (1998), Viana et al. (2017) e Vianin (2013).

A abordagem de leitura como uma atividade de construção de sentidos, tal como vem sendo divulgada por Koch e Elias (2006) e Marcuschi (2008), oferece pressupostos teóricos para um trabalho visando ao desenvolvimento de habilidades de leitura dos alunos. Um dos motivos é porque "Compreender bem um texto não é uma atividade natural nem uma herança genética; nem uma ação individual e isolada do meio e da sociedade em que se vive. Compreender exige habilidade, interação [autor-texto-leitor] e trabalho" (MARCUSCHI, 2008, p. 229-230). A leitura precisa ser ensinada.

A perspectiva sociocognitiva de leitura fundamenta-se "em uma concepção sociocognitivo-interacional de língua que privilegia os sujeitos e seus conhecimentos em processo de interação", como afirmam Koch e Elias (2006, p. 12). Sendo a língua, em suas manifestações de enunciados concretos, um fenômeno bastante complexo, estruturado em vários níveis, dialógico e sensível ao contexto (MARCUSCHI, 2008), a compreensão na leitura não é uma tarefa que se realiza numa etapa única e simples. Koch e Elias (2006) explicam que:

A leitura é, pois, uma atividade interativa altamente complexa de produção de sentidos, que se realiza evidentemente com base nos elementos linguísticos presente na superfície textual e na sua forma de organização, mas requer a mobilização de um vasto conjunto de saberes no interior do evento comunicativo (KOCH; ELIAS, 2006, p. 11).

A complexidade da compreensão decorre, entre vários fatores, de o leitor precisar relacionar as informações do texto - que deve ser identificado como um exemplar de um determinado gênero discursivo - com seus conhecimentos prévios. Esses incluem conhecimentos linguísticos (léxico, estruturas sintáticas, recursos da língua escrita), enciclopédicos (tudo o que se sabe sobre variados temas, inclusive sobre o tema do texto a ser lido), sobre o contexto ou situação de comunicação que o texto estabelece, sobre outros textos a respeito do tema, sobre normas (institucionais, culturais, sociais) (KOCH; ELIAS, 2006; MARCUSCHI, 2008).

Enfim, todos os conhecimentos que o leitor conseguir mobilizar durante a leitura e relacionar com as informações explicitadas no texto (informações da superfície textual, inclusive os elementos não verbais) serão fundamentais para a construção de sentidos, a partir de inferências. O leitor que tem objetivo(s), habilidades de leitura, mentalidade estratégica, consegue utilizar bem seus conhecimentos prévios na interação com o texto (SOLÉ, 1998). Leitores com diferentes perfis alcançam níveis distintos de compreensão do mesmo texto. Destacam-se, portanto, dos estudos sobre compreensão de texto escrito, os conceitos de conhecimentos prévios, objetivo de leitura, estratégia de leitura, habilidade e inferência, que contribuem sobremaneira para uma pedagogia da leitura em aulas de Língua Portuguesa.

\section{LINHA DÁGUA}


O que se sabe atualmente sobre leitura, após décadas de estudos sobre o tema, é que a decodificação é uma etapa importante na leitura, alcançada pelo aluno na sua fase de alfabetização. Portanto, não se descarta a decodificação do processo de compreensão, mas se entende que há outros níveis envolvidos (SOUSA; GABRIEL, 2009). Faz sentido incluir algumas perguntas sobre informações explícitas do texto, cujas respostas serão cópia ou paráfrase de partes do texto, em atividades de compreensão para alunos em fase inicial do processo de leitura, para verificar sua habilidade de localizar informações explícitas em um texto. As atividades de leitura, no entanto, devem priorizar níveis inferenciais com base em relações entre partes do texto, conhecimentos prévios, reflexões e posicionamento crítico.

Inferências são atividades cognitivas que o leitor ou ouvinte realiza quando reúne algumas informações conhecidas para chegar a outras informações novas (MARCUSCHI, 2008). A construção de sentidos para um texto depende da atividade inferencial. Toda a gama de habilidades de um leitor, exceto a habilidade de decodificação, envolve algum tipo de inferência. Vargas (2015) explica que inferência é um processo de geração ou criação de significados novos em relação ao texto e aos conhecimentos prévios do leitor. É possível concluir que inferências são os significados novos resultantes da associação de informações do texto com conhecimentos prévios do leitor. Não é qualquer afirmação sobre o texto, no entanto, que pode ser considerada uma inferência.

Marcuschi (2008) classifica as inferências pelo grau de complexidade. Há inferências de base textual, por vezes óbvias, baseadas, sobretudo, nas relações lógicas entre as proposições do texto. O leitor observa que o texto apresenta determinada afirmação aqui, depois apresenta outra afirmação mais adiante, e, relacionando as duas, chega a uma conclusão. Assim, faz uma inferência. Há inferências semânticas, ainda de base textual, dependentes do conhecimento de itens lexicais e das relações semânticas estabelecidas entre eles. Há inferências de base contextual, que o autor denomina de pragmáticas-cognitivas, e que são dependentes de conhecimentos, experiências, crenças, ideologias e valores individuais. Essas são mais complexas.

Pensando na leitura de gêneros discursivos na escola, Lopes-Rossi (2018) acrescenta um outro nível de inferências, relativo ao gênero discursivo do qual o texto faz parte. São inferências de mais alta complexidade, necessárias ao posicionamento crítico do leitor, dependentes do conhecimento relacionado ao gênero. A partir de aspectos do gênero mencionados na seção anterior, o leitor pode inferir, por exemplo, como a construção composicional e o estilo do texto foram concebidos pelo autor para realizar seu propósito; que relações dialógicas o texto estabelece com outros textos e com discursos presentes e passados; que atitudes responsivas, prejuízos ou benefícios o texto pode provocar nas pessoas ou na sociedade; e como o tema foi abordado em relação a posicionamentos que se podem observar no contexto sócio-histórico de produção e de circulação do texto, inclusive, em relação a posicionamentos do autor.

\section{LINHA DÁGUA}


Leitores considerados pouco proficientes falham de alguma maneira nesse processo inferencial. Podem, no entanto, ser ajudados na percepção dos elementos do texto, na ampliação dos conhecimentos prévios necessários à leitura, no estabelecimento de objetivos de leitura, no monitoramento de sua compreensão e no uso de suas habilidades leitoras.

O ensino de habilidades de leitura recebeu críticas na sua versão mais antiga, em que as estratégias eram ensinadas como receitas fixas a um sujeito que deveria mobilizar os conhecimentos estruturados em sua mente, para solucionar determinados problemas de leitura, muitas vezes, relativos a aspectos estruturais e superficiais do texto. Essas críticas foram superadas pelos estudos mais recentes da cognição e do ensino de leitura, que situam e reconfiguram sócio-historicamente o leitor, o texto e os conhecimentos prévios.

Koch (2005) explica que as ciências cognitivas clássicas tendiam a explicar os processos cognitivos de forma desvinculada dos processos que acontecem no ambiente, no contexto social em que interagem os sujeitos. A cultura e a vida social eram vistas como componentes do ambiente; e a relação entre cognição e cultura se baseava, em grande parte, no conjunto de noções e de procedimentos que os sujeitos pudessem armazenar em suas mentes, de forma individual e passiva. Formulações mais recentes das ciências cognitivas incorporam aspectos sociais, culturais e interacionais à constituição do processamento cognitivo. É uma visão que não separa mente e corpo, porque assume que "nossa cognição é o resultado de nossas ações e de nossas capacidades sensório-motoras" (KOCH, 2005, p. 99). Nessa abordagem sociocognitiva, "não há possibilidades integrais de pensamento ou domínios cognitivos fora da linguagem, nem possibilidades de linguagem fora de processos interativos humanos" (KOCH, 2005, p. 100). Gerhardt (2006) também explica que, pela ótica sociocognitiva, o desenvolvimento da inteligência e a aquisição de novos conhecimentos se dão a partir da interação com o contexto, num sentido bastante amplo do termo. O conceito de conhecimentos prévios, portanto, foi ressignificado e ampliado.

Transferindo essas considerações para práticas de leitura de gêneros discursivos e retomando a importância do caráter social, situado e dialógico da linguagem humana na concepção bakhtiniana, fica evidente porque as situações escolares de leitura não podem ficar na interpretação superficial dos textos e precisam ser um espaço de diálogo amplo do leitor com o texto, com outros textos e com outros leitores.

O ensino de estratégias de leitura, explica Solé (1998), deve envolver aspectos de metacognição, ou seja, de conhecimento sobre a aprendizagem, sobre os principais aspectos envolvidos na leitura e sobre as causas das dificuldades, além da busca consciente de resolução de problemas de compreensão. A mediação do professor deve ser no sentido de contribuir para que o aluno possa desenvolver uma mentalidade estratégica, que facilite a identificação, a análise e a busca de soluções. O professor proporciona andaimes aos alunos, que podem ser retirados à medida que as estratégias forem sendo interiorizadas.

\section{LINHA DÁGUA}


Muitos autores defendem essa prática, como Carrell (1998), que explica que as estratégias metacognitivas que vão sendo interiorizadas passam a ser usadas de forma automática e se transformam em habilidades de leitura. Portanto, para esse autor e para Solé (1998), baseados em vários outros, ensinam-se estratégias metacognitivas de leitura, não habilidades. As habilidades referem-se a formas de processamento da informação (compreensão) e a comportamentos durante a leitura que ocorrem por um processo automático, sem que o leitor pense sobre o que está fazendo e o porquê. Nessa perspectiva, as 58 habilidades de leitura relacionadas pela BNCC (BRASIL, 2018) para os $6^{\circ}$ a $9^{\circ}$ anos devem ser entendidas como resultado da prática constante e organizada de muitas estratégias metacognitivas de leitura.

E como se situam as estratégias em relação a procedimentos? A BNCC (BRASIL, 2018) menciona esses conceitos, mas não os distingue. Solé (1998, p. 68) explica que uma definição para procedimento é a de "um conjunto de ações ordenadas e finalizadas, isto é, dirigidas à consecução de uma meta". Nos procedimentos, podem ser indicadas destrezas, técnicas ou estratégias. Para essa autora, no ensino de leitura, é preciso construir procedimentos mais gerais que incluam as estratégias de leitura.

Articulando propriedades constitutivas de gêneros discursivos e conceitos da abordagem sociocognitiva de leitura, Lopes-Rossi $(2015$; 2018) propõe a organização de práticas de leitura em sala de aula a partir de quatro procedimentos: 1) acionamento e ampliação de conhecimentos sobre o gênero e o tema; 2) leitura rápida dos elementos mais destacados para identificação do tema e formulação de objetivos para a leitura do texto completo; 3) leitura inferencial mais complexa, com enfoque em partes específicas do texto e características constitutivas do gênero; 4) apreciação crítica da abordagem do tema e percepção de relações dialógicas que o texto estabelece. A autora comenta que esse é um percurso que mobiliza os principais conceitos teóricos envolvidos na leitura e na constituição dos gêneros discursivos e que possibilita desde a compreensão de proposições básicas do texto até o posicionamento crítico do leitor. Esses procedimentos serão retomados nas considerações finais desta pesquisa.

\section{Habilidades de leitura específicas para $6^{\circ}$ a $9^{\circ}$ ano}

O leitor da BNCC (BRASIL, 2018) interessado em implementar em sala de aula o Eixo Leitura, após interpretar o quadro geral das dimensões do tratamento das práticas leitoras, apresentado e discutido na seção 1, ainda precisa interpretar os quadros específicos para os anos finais do Ensino Fundamental, $6^{\circ}$ a $9^{\circ}$ ano, apresentados nas páginas 136 a 191 do documento. Esses quadros apresentam três colunas: práticas de linguagem, objetos de conhecimento e habilidades para cada campo de atuação social (jornalístico-midiático, atuação na vida pública, práticas de estudo e pesquisa, artístico-literário). Os objetos de conhecimento referentes à prática de linguagem Leitura são reproduzidos no quadro 2, a seguir.

\section{LINHA D'ÁGUA}


Quadro 2. Objetos de conhecimento relacionados para a prática de linguagem Leitura/Escuta

\begin{tabular}{|c|c|c|c|}
\hline Objetos de conhecimento & $\begin{array}{l}6^{\circ} \text { ao } \\
9^{\circ} \text { ano }\end{array}$ & $\begin{array}{l}6^{\circ} \text { e } 7^{\circ} \\
\text { anos }\end{array}$ & $\begin{array}{l}8^{\circ} \text { e } 9^{\circ} \\
\text { anos }\end{array}$ \\
\hline Apreciação e réplica; relação entre gêneros e mídias & $\mathrm{X}$ & & \\
\hline Estratégia de leitura: apreender os sentidos globais do texto & $\mathrm{X}$ & & $\mathrm{X}$ \\
\hline Efeitos de sentido & $\mathrm{X}$ & $\mathrm{X}$ & $\mathrm{X}$ \\
\hline $\begin{array}{l}\text { Reconstrução das condições de produção e circulação e adequação do } \\
\text { texto à construção composicional e ao estilo de gênero }\end{array}$ & $\mathrm{X}$ & & \\
\hline Apreciação e réplica & $\mathrm{X}$ & $\mathrm{X}$ & $\mathrm{X}$ \\
\hline Relação entre textos & $\mathrm{X}$ & $\mathrm{X}$ & $\mathrm{X}$ \\
\hline $\begin{array}{l}\text { Estratégias e procedimentos de leitura } \\
\text { (em textos legais e normativos; em textos reivindicatórios ou } \\
\text { propositivos; apreender os sentidos globais do texto) }\end{array}$ & $\mathrm{X}$ & $\mathrm{X}$ & $\mathrm{X}$ \\
\hline Relação do verbal com outras semioses & $\mathrm{X}$ & & \\
\hline Procedimentos e gêneros de apoio à compreensão & $\mathrm{X}$ & & \\
\hline $\begin{array}{l}\text { Reconstrução da textualidade e compreensão dos efeitos de sentidos } \\
\text { provocados pelos usos de recursos linguísticos e multissemióticos }\end{array}$ & $\mathrm{X}$ & & $\mathrm{X}$ \\
\hline Adesão às práticas de leitura & $\mathrm{X}$ & & \\
\hline Reconstrução do contexto de produção e circulação e recepção & & $\mathrm{X}$ & $\mathrm{X}$ \\
\hline $\begin{array}{l}\text { Caracterização do campo jornalístico e relação entre os gêneros em } \\
\text { circulação, mídias e práticas da cultura digital }\end{array}$ & & $\mathrm{X}$ & $\mathrm{X}$ \\
\hline Distinção de fato e opinião & & $\mathrm{X}$ & \\
\hline Estratégia de leitura: identificação de teses e argumentos & & $\mathrm{X}$ & \\
\hline Exploração da multissemiose & & $\mathrm{X}$ & $\mathrm{X}$ \\
\hline $\begin{array}{l}\text { Relação entre contexto de produção e características composicionais e } \\
\text { estilísticas dos gêneros }\end{array}$ & & $\mathrm{X}$ & $\mathrm{X}$ \\
\hline Curadoria de informação & & $\mathrm{X}$ & $\mathrm{X}$ \\
\hline $\begin{array}{l}\text { Contexto de produção, circulação e recepção de textos e práticas } \\
\text { relacionadas à defesa de direitos e à participação social }\end{array}$ & & $\mathrm{X}$ & $\mathrm{X}$ \\
\hline
\end{tabular}

Fonte: Elaborado pela pesquisadora

A lista se refere aos quatro campos de atuação social. O documento afirma que os objetos de conhecimento são "entendidos como conteúdos, conceitos e processos" (BRASIL, 2018, p. 28). Causa estranheza que algumas dimensões das práticas leitoras do quadro das páginas 72 a 74 apareçam como objetos de conhecimento nas páginas 136 a 191, ainda que com redação parcialmente modificada. O conceito "objeto de conhecimento" não está claro, mas percebe-se que remete a aspectos da constituição dos gêneros discursivos e a procedimentos de leitura. Muito provavelmente, a implementação desses objetos de conhecimento na sala de aula fica prejudicada, pelo fato de haver uma lista para o bloco $6^{\circ}$ ao $9^{\circ}$ ano e duas listas para os $6^{\circ}$ e $7^{\circ}$ anos e $8^{\circ}$ e $9^{\circ}$ anos. As listas não são inteiramente coincidentes nem complementares.

A alguns objetos de conhecimento corresponde uma habilidade, a outros correspondem várias. No total, são 18 habilidades de leitura para o $6^{\circ}$ ao $9^{\circ}$ ano. Para os anos específicos, são 40 habilidades, sendo duas apenas para o $6^{\circ}$ ano, duas apenas para o $7^{\circ}$ ano e 18 comuns para esses dois anos. $\mathrm{O}$ mesmo ocorre para o $8^{\circ}$ e o $9^{\circ}$ anos. Não se percebe a relação entre as 18 
habilidades propostas para o conjunto dos quatro anos e as 20 habilidades para os anos específicos, mesmo comparando as habilidades com o mesmo número. Por exemplo, são reproduzidas a seguir as habilidades de número 01 do Campo Jornalístico-midiático para o $6^{\circ} \mathrm{a}$ $9^{\circ}$ ano, para o $6^{\circ}$ ano e para o $7^{\circ}$ ano:

(EF69LP01) Diferenciar liberdade de expressão de discursos de ódio, posicionando-se contrariamente a esse tipo de discurso e vislumbrando possibilidades de denúncia quando for o caso. (BRASIL, 2018, p. 141)

(EF06LP01) Reconhecer a impossibilidade de uma neutralidade absoluta no relato de fatos e identificar diferentes graus de parcialidade/imparcialidade dados pelo recorte feito e pelos efeitos de sentido advindos de escolhas feitas pelo autor, de forma a poder desenvolver uma atitude crítica frente aos textos jornalísticos e tornar-se consciente das escolhas feitas enquanto produtor de textos. (BRASIL, 2018, p. 163)

(EF07LP01) Distinguir diferentes propostas editoriais - sensacionalismo, jornalismo investigativo etc. -, de forma a identificar os recursos utilizados para impactar/chocar o leitor que podem comprometer uma análise crítica da notícia e do fato noticiado. (BRASIL, 2018, p. 163)

As primeiras habilidades para o $8^{\circ}$ e $9^{\circ}$ ano não foram reproduzidas, mas também são diferentes dessas. A análise das 58 habilidades permite concluir que o teor delas se justifica e é claramente compreensível, é coerente com a concepção de linguagem adotada pelo documento, com os principais aspectos dos gêneros discursivos produzidos nos campos priorizados, com a proposta de multiletramentos e com os valores éticos propostos para a Educação Básica. No entanto, a quantidade e os conjuntos de habilidades nem coincidentes nem complementares apresentados para o $6^{\circ}$ ao $9^{\circ}$ ano e para os $6^{\circ}$ e $7^{\circ}$ anos e $8^{\circ}$ e $9^{\circ}$ anos podem confundir o leitor e dificultar o planejamento das atividades de leitura.

Finalmente, cabe uma palavra sobre os gêneros discursivos mencionados nos quadros, para cada campo de atuação social. Foram 25 para o Campo jornalístico-midiático; 18 para o Campo de atuação na vida pública; 12 para o Campo das práticas de estudo e pesquisa; e um número indeterminado para o Campo artístico-literário, porque, para esse, foram recomendados gêneros literários e artísticos diversos. São, portanto, 55 gêneros dos três campos acrescidos de vários outros possíveis dentre os literários e artísticos. É uma quantidade muito grande, impossível de ser abordada na totalidade. Também não é explicitado no documento o quanto dessa imensa lista pode ou deve integrar os currículos.

\section{Uma articulação possível dos conceitos em práticas de leitura}

Os aspectos teóricos sobre gêneros discursivos e sobre leitura que emergem da análise da BNCC (BRASIL, 2018) precisam ser articulados visando a práticas bem fundamentadas e exequíveis em sala de aula. E isso não pode ser pensado gênero por gênero, ano por ano, com dezenas de configurações diferentes. Os procedimentos de leitura propostos por Lopes-Rossi

\section{LINHA DÁGUA}


(2015; 2018) organizam um trabalho baseado nesses pressupostos teóricos e podem ser adaptados para contemplar as habilidades que a BNCC (BRASIL, 2018) prescreve para a Educação Básica, além de outras pertinentes à formação do leitor. Nesse sentido, esta pesquisa propõe o seguinte planejamento de práticas de leitura de gêneros discursivos em sala de aula:

Quadro 3. Procedimentos de leitura de gêneros discursivos

\begin{tabular}{|c|c|c|}
\hline $\begin{array}{l}\text { Procedimentos de } \\
\text { leitura }\end{array}$ & $\begin{array}{l}\text { Características constitutivas do } \\
\text { gênero discursivo mobilizadas no } \\
\text { procedimento e que se relacionam } \\
\text { aos objetos de conhecimento } \\
\text { mencionados pela BNCC }\end{array}$ & $\begin{array}{l}\text { Estratégias metacognitivas de leitura } \\
\text { para desenvolver as habilidades } \\
\text { previstas pela BNCC, entre outras }\end{array}$ \\
\hline $\begin{array}{l}\text { 1) Acionamento de } \\
\text { conhecimentos } \\
\text { prévios }\end{array}$ & $\begin{array}{l}\text { Elementos do contexto } \\
\text { enunciativo: } \\
\text { - propósito comunicativo } \\
\text { (finalidade do gênero na } \\
\text { sociedade) } \\
\text { - condições de produção } \\
\text { - temáticas que o gênero pode } \\
\text { abordar } \\
\text { - condições de circulação e } \\
\text { recepção } \\
\text { Tema do texto a ser lido }\end{array}$ & $\begin{array}{l}\text { Verificar as habilidades que se encaixam } \\
\text { nesse procedimento, dependendo do } \\
\text { campo a que pertence o texto a ser lido, } \\
\text { e procurar mobilizá-las com: } \\
\text { Perguntas orais; diálogo com os alunos; } \\
\text { pesquisa em fontes diversas para } \\
\text { ampliar o conhecimento sobre o gênero } \\
\text { e sobre o tema; exposição de resultados } \\
\text { da pesquisa com uso de recursos } \\
\text { tecnológicos pertinentes às atividades, } \\
\text { entre outras estratégias didáticas. }\end{array}$ \\
\hline $\begin{array}{l}\text { 2) Identificação do } \\
\text { tema do texto (se } \\
\text { possível) e } \\
\text { formulação de } \\
\text { objetivos para a } \\
\text { leitura do texto } \\
\text { completo }\end{array}$ & $\begin{array}{l}\text { Elementos composicionais não } \\
\text { verbais } \\
\text { Elementos verbais destacados }\end{array}$ & $\begin{array}{l}\text { Verificar as habilidades que se encaixam } \\
\text { nesse procedimento, dependendo do } \\
\text { campo a que pertence o texto a ser lido, } \\
\text { e procurar mobilizá-las com: } \\
\text { Leitura rápida dos elementos mais } \\
\text { destacados; perguntas motivadoras de } \\
\text { inferências pela leitura do não verbal e } \\
\text { pela leitura do verbal em destaque; } \\
\text { levantamento de hipóteses sobre o texto } \\
\text { e de curiosidades ou de motivos que se } \\
\text { configuram como objetivos de leitura. }\end{array}$ \\
\hline $\begin{array}{l}\text { 3) Leitura } \\
\text { inferencial mais } \\
\text { complexa, com } \\
\text { enfoque em partes } \\
\text { específicas do texto } \\
\text { e características } \\
\text { constitutivas do } \\
\text { gênero }\end{array}$ & $\begin{array}{l}\text { Informações específicas sobre o } \\
\text { tema } \\
\text { Forma de desenvolvimento do } \\
\text { tema e do texto, de acordo com o } \\
\text { gênero discursivo } \\
\text { Recursos linguísticos e } \\
\text { expressivos } \\
\text { Mecanismos de coesão } \\
\text { Intertextualidade } \\
\text { Elementos composicionais } \\
\text { específicos de cada gênero } \\
\text { Estilo do gênero e do texto } \\
\text { Elementos multissemióticos }\end{array}$ & $\begin{array}{l}\text { Verificar as habilidades que se encaixam } \\
\text { nesse procedimento, dependendo do } \\
\text { campo a que pertence o texto a ser lido, } \\
\text { e procurar mobilizá-las com: perguntas; } \\
\text { atividades de compreensão diversas; } \\
\text { discussões que provoquem inferências e } \\
\text { compreensão detalhada do texto como } \\
\text { um enunciado completo e situado na sua } \\
\text { esfera de enunciação, em diálogo com } \\
\text { outros discursos, construído com } \\
\text { elementos que atendem as exigências da } \\
\text { situação de comunicação. }\end{array}$ \\
\hline
\end{tabular}




\begin{tabular}{|c|c|c|}
\hline $\begin{array}{l}\text { 4) Apreciação } \\
\text { crítica da } \\
\text { abordagem do } \\
\text { tema; percepção } \\
\text { das relações } \\
\text { dialógicas } \\
\text { constitutivas do } \\
\text { enunciado; atitudes } \\
\text { responsivas do } \\
\text { leitor. }\end{array}$ & $\begin{array}{l}\text { Quantidade e qualidade das } \\
\text { informações } \\
\text { Uso dos recursos linguísticos e } \\
\text { multissemióticos } \\
\text { Temas, discursos, ideologias } \\
\text { atuais e do passado que ecoam no } \\
\text { texto } \\
\text { Possibilidade de motivar leitores a } \\
\text { se manifestarem pelos mais } \\
\text { variados motivos; possíveis } \\
\text { atitudes responsivas dos leitores }\end{array}$ & $\begin{array}{l}\text { Verificar as habilidades que se encaixam } \\
\text { nesse procedimento, dependendo do } \\
\text { campo a que pertence o texto a ser lido, } \\
\text { e procurar mobilizá-las com: perguntas } \\
\text { orais ou escritas; reflexões dos alunos; } \\
\text { comparações com outros textos; } \\
\text { produções de naturezas diversas que } \\
\text { dialoguem com o texto lido e/ou } \\
\text { expressem atitudes responsivas a ele; } \\
\text { encaminhamento de pesquisas ou } \\
\text { atividades futuras para maior } \\
\text { conhecimento do tema. }\end{array}$ \\
\hline
\end{tabular}

Fonte: Elaborado pela pesquisadora a partir de Lopes-Rossi $(2015 ; 2018)$

Esse quadro não explicita os objetos de conhecimento prescritos pela BNCC (BRASIL, 2018) para as Práticas de leitura, porque se constatou que não são muito claros. No entanto, como são definidos a partir de pressupostos teóricos sobre gêneros discursivos e sobre leitura, ficam contemplados nos procedimentos propostos no quadro 3. As habilidades de leitura também podem ser mobilizadas nesses procedimentos, seja qual for o exemplar de gênero discursivo alvo da leitura.

\section{Considerações finais}

Conclui-se que há caminhos possíveis para a implementação da proposta de práticas de leitura da BNCC (BRASIL, 2018) em seus aspectos essenciais, porque ela se fundamenta, ainda que não explicite, na perspectiva bakhtiniana (enunciativo-discursiva) de linguagem e na concepção sociodiscursiva de leitura. Esses pressupostos já vêm subsidiando práticas didáticas exitosas. Os conceitos teóricos que se destacaram e que, portanto, precisam fazer parte do repertório dos professores de Língua Portuguesa são: gênero discursivo, novos e multiletramentos, multissemiose, dialogia, intertextualidade, interdiscursividade, coesão referencial, coesão sequencial, organização textual, inferência, procedimentos de leitura, estratégias metacognitivas e habilidades de leitura.

O grande número de gêneros discursivos prescritos é impossível de ser abordado na totalidade, por meio de práticas de leitura teoricamente bem fundamentadas. Embora a BNCC (BRASIL, 2018) não explicite quantos gêneros podem ou devem integrar os currículos, um recorte é inevitável. As dimensões das práticas leitoras e os objetos de conhecimento não se definem com clareza e se sobrepõem em alguns aspectos. As 58 habilidades de leitura prescritas apresentam um teor mais claro, coerente com as concepções de linguagem e de leitura adotadas pelo documento e com os valores éticos propostos para a Educação Básica.

O desenvolvimento de habilidades leitoras dos alunos - formas automatizadas de processamento da informação (compreensão) e de comportamentos durante a leitura - requer, de acordo com a pesquisa bibliográfica empreendida, prática constante e organizada de muitas

\section{LINHA DÁGUA}


estratégias metacognitivas, mediadas pela ação docente. Um caminho para a didatização do conjunto de pressupostos teóricos disposto na BNCC (BRASIL, 2018) visando a esse objetivo foi proposto nesta pesquisa, na forma de procedimentos de leitura. Espera-se, assim, contribuir para o planejamento e para a realização de uma pedagogia da leitura bem-sucedida e motivadora.

\section{Referências}

BAKHTIN, M. Estética da criação verbal. Trad. Paulo Bezerra. 4.ed. São Paulo: Martins Fontes, 2003.

BAKHTIN, M. M. (VOLOCHÍNOV, V. N.). Marxismo e Filosofia da linguagem. 12 ed. São Paulo: Hucitec, 2006.

BRAIT, B. O texto nas reflexões de Bakhtin e do Círculo. In: BATISTA, R. de O. (org.). $O$ texto e seus conceitos. São Paulo: Parábola, 2016. p. 13-30.

BRASIL. Secretaria de Educação Fundamental. Parâmetros Curriculares Nacionais. Terceiro e quarto ciclos do ensino fundamental: língua portuguesa. Brasília: MEC/SEF. 1998.

BRASIL. Ministério da Educação; Secretaria de Educação Básica. Base Nacional Comum Curricular (BNCC). Brasília: MEC; SEB, 2018. Disponível em: http://basenacionalcomum.mec.gov.br/images/BNCC EI EF 110518 versaofinal site.pdf. Acesso em: 30 abr. 2019.

BRASIL. Ministério da Educação. Saeb: Resultados. Brasília: INEP, 2020. Disponível em: https://www.gov.br/inep/pt-br/areas-de-atuacao/avaliacao-e-exameseducacionais/saeb/resultado. Acesso em: 20 abr. 2021.

BUTLEN, M. A leitura: uma prática cultural polimorfa. Leitura: Teoria e prática, Campinas, v. 33, n. 32, p. 13-34, 2015. Disponível em: https://ltp.emnuvens.com.br/ltp/article/view/408/254. Acesso em: 18 nov. 2020.

CADERNOS PUC 16. Linguística (Leitura). São Paulo: EDUC - Editora da PUC; Cortez, 1983.

CARRELL, P. The language teacher. Can reading strategies be successfully taught? Georgia State University, $1998 . \quad$ Disponível em: http://www.jaltpublications.org/tlt/files/98/mar/carrell.html. Acesso em 20 nov. 2020.

DIONÍSIO, A. P. Gêneros multimodais e multiletramento. In: KARWOSKI, A. M.; GAYDECZKA, B.; BRITO, K. S. (org.). Gêneros textuais: reflexões e ensino. Palmas: Kaygangue, 2005. p. 159-177.

FÁVERO, L. L. Coesão e coerência textuais. 11 ed. São Paulo: Ática, 2006.

FIORIN, J. L. Introdução ao pensamento de Bakhtin. São Paulo: Ática, 2006.

FIORIN, J. L. Leitura e dialogismo. In: ZILBERMAN, R.; RÖSING, T. M. K. (org.). Escola e leitura: velha crise, novas alternativas. São Paulo: Global, 2009. p. 41-59.

GERALDI, J. W. (org.) O texto na sala de aula: leitura \& produção. 2. ed. Cascavel: Assoeste, 1984.

\section{LINHA DÁGUA}


GERHARDT, A. F. L. M. Uma visão sociocognitiva da avaliação em textos escolares. Educação e sociedade, Campinas, v. 27, n. 97, p. 1181-1203, set./dez. 2006. DOI: https://doi.org/10.1590/S0101-73302006000400006. Acesso em: 12 abr. 2021.

KATO, M. A. O aprendizado da leitura. São Paulo: Martins Fontes, 1985.

KOCH, I. G.V. A construção sociocognitiva da referência. In: MIRANDA, N. S.; NAME, M. C. (org.). Linguística e cognição. Juiz de Fora: Ed. UFJR, 2005.

KOCH, I. V.; ELIAS, V. M. Ler e compreender: os sentidos do texto. São Paulo: Contexto, 2006.

LAKATOS, E. M.; MARCONI, M. de A. Fundamentos da Metodologia Científica. 3.ed. rev. e ampl. São Paulo: Atlas, 1991.

LEMKE, J. L. Letramento metamidiático: transformando significados e mídias. Trabalhos em Linguística Aplicada, v. 49, n. 2, p. 455-479, jul./dez. 2010. Disponível em: https://periodicos.sbu.unicamp.br/ojs/index.php/tla/article/view/8645275. Acesso em: 13 mar. 2019.

LOPES-ROSSI, M. A. G. Aspectos teóricos e sequências didáticas para a produção escrita de gêneros discursivos. Letras \& Letras, v. 31, p. 132-157, 2015. Disponível em: http://www.seer.ufu.br/index.php/letraseletras/article/view/30598/16710. Acesso em: 13 mar. 2019.

LOPES-ROSSI, M. A. G. Sequência didática para leitura de reportagem. In: BARROS, E. M. D. de; STRIQUER, M. dos S. D.; STORTO, L. J. (org.). Propostas didáticas para o ensino da Lingua Portuguesa. Campinas: Pontes, 2018, v. 1, p. 71-90.

MARCUSCHI, L. A. Produção textual, análise de gêneros e compreensão. São Paulo: Parábola, 2008.

OLIVEIRA, M. B. F. de. Contribuições do círculo de Bakhtin ao ensino da língua materna. Revista do GELNE, v. 4, $\mathrm{n}^{\mathrm{o}} 1 / 2$, p. 129-131, 2002. Disponível em: https://periodicos.ufrn.br/gelne/article/view/9135. Acesso em: 12 abr. 2021.

PEREIRA, M. T. G. Leitura e Intertextualidade: o cruzamento de leituras e práticas textuais. In: VALENTE, A. (Org.). Língua, Linguística e Literatura. Rio de Janeiro: Ed. UERJ, 1998. p. 279-291.

ROJO, R. Letramentos escolares: coletâneas de textos nos livros didáticos de Língua Portuguesa. Perspectiva, Florianópolis, v. 28, n. 2, p. 433-465, 2010. DOI: https://doi.org/10.5007/2175-795X.2010v28n2p433. Acesso em: 22 fev. 2021.

SOLE, I. Estratégias de leitura. 6. ed. Porto Alegre: Artmed, 1998.

SOUSA, L. B. de; GABRIEL, R. Fundamentos cognitivos para o ensino da Leitura. Signo, v. 34, n. 57. Santa Cruz do Sul, p. 47-63, jul./dez. 2009. DOI: https://doi.org/10.17058/signo.v34i57.1201. Acesso em: 03 abr. 2021.

TAGLIEBER, L. K. Critical reading and critical thinking: the state of the art. Ilha do Desterro, n. 38. Florianópolis, p. 15-37, jan./jun. 2000. DOI: https://doi.org/10.5007/\%25x. Acesso em: 25 mar. 2021. 
TODOROV, J. C.; MOREIRA, M. B. O conceito de motivação na psicologia. Revista Brasileira de Terapia Comportamental e Cognitiva, São Paulo, v. 7, n. 1, p. 119-132, jun. 2005. Disponível em: http://pepsic.bvsalud.org/scielo.php?script=sci abstract\&pid=S151755452005000100012. Acesso em: 28 abr. 2021.

VARGAS, D. da S. Por uma visão cognitivista do processo de inferenciação em leitura. Ciências \& Cognição, v. 20, n. 2, p. 313-330, 2015. Disponível em: http://www.cienciasecognicao.org/revista/index.php/cec/article/view/1024. Acesso em: 23 mar. 2021.

VIANA, F. L. et al. O ensino explícito da compreensão da leitura. Análise do impacto de um programa de intervenção. Revista Brasileira de Educação, Rio de Janeiro, v. 22, n. 71, p. 1-30, 2017. DOI: https://doi.org/10.1590/s1413-24782017227172. Acesso em: 15 jan. 2021.

VIANIN, P. Estratégias de ajuda a alunos com dificuldades de aprendizagem. Tradução de Fátima Murad. Porto Alegre: Penso, 2013.

Recebido: 30/04/2021.

Aprovado: 02/08/2021. 